\title{
Optimal capacitor placement in smart distribution systems to improve its maximum loadability and energy efficiency
}

\author{
Ikbal Ali ${ }^{1 *}$, Mini S. Thomas ${ }^{1}$, Pawan Kumar ${ }^{2}$ \\ ${ }^{1 *}$ Department of Electrical Engineering, FET Jamia Millia Islamia New Delhi, INDIA \\ ${ }^{2}$ Department of Electrical and Electronics Engineering, GCET Greater Noida, INDIA \\ e-mail:iqali_in@yahoo.com and ${ }^{1}$ min_st@yahoo.com, ${ }^{2}$ pawanror@gmail.com
}

\begin{abstract}
An energy efficient power distribution network can provide cost-effective and collaborative platform for supporting present and future smart distribution system requirements. Energy efficiency in distribution systems is achieved through reconfiguration of distributed generation and optimal capacitor placement. Though several techniques have been reported earlier for optimal capacitor placement, this paper presents an improved technique based on combining Power Loss Index (PLI) and Maximum Loadability Index $(M L I)$. It takes care of critical compensation to maximize loadability and loss reduction. Improved performance results of the new technique have been demonstrated on an IEEE 15 bus distribution system for different load models. It is demonstrated that the load models have significant effect on selecting the capacitor size. The improvement in the loadability limit in constant impedance loads and the reduction in power loss in constant power loads is more than any other load models. The simultaneous improvement in loadability limit and loss reduction enhances energy efficiency in distribution systems by releasing power demand and feeder capacity.
\end{abstract}

Keywords: Critical Compensation, Load Models, Maximum Loadability, Optimal Capacitor Placement, Power Loss Index.

DOI: http://dx.doi.org/10.4314/ijest.v3i8.21

\section{Introduction}

Energy efficiency, in limited energy resources scenario, is considered as a source of energy in a distribution system. The improvement in energy efficiency of distribution systems by reconfiguring the network is limited, as it is associated with the improvement of node voltages profile only, while the active and reactive power flow remaining the same. The optimal capacitor placement plays a very significant role in improving system efficiency as it reduces power loss, releases the kVA capacities of distribution apparatus, improves power factor, system voltage profile and maximum loadability limit.

Different methods have been proposed for capacitor placement in a radial distribution systems based upon power loss index (Satyanarayana et al., 2003), ant colony optimization (Chang, 2008), fuzzy logics (Bhattacharya et al., 2009; Mekhamer et al., 2003), non-linear programming approach (Leonardo et al., 2010), voltage stability index (Baran and Wu, 1989a), particle swarm optimization (Zou et al., 2009), and genetic algorithms (Haghifam et al., 2007). Haque (1999) has given the technique for capacitor placement with the objective to maximize the reduction of power loss only. The size and location of capacitor can be found by considering the voltage profile improvement and maximum loss reduction. This can be done by using soft computing methods like fuzzy logic, particle swarm optimization and genetic algorithms, however, in actual practice, the placement of capacitor at some nodes may lead to over compensation. The over compensation not only causes extra loss in the system, but also partially affects the stability of the system. This paper has evolved an improved technique based on combining Power Loss Index $(P L I)$ and Maximum Loadability Index $(M L I)$ which takes care of critical compensation to maximize loadability and loss reduction. $M L I$ based technique also takes the system loadability in to consideration while selecting optimal capacitor size so that the existing system may supply more load demand in future. 
The aim of the present research work is to examine the effect of optimal size and location of capacitor and to suggest a new technique to improve the loadability (i.e. $M L I$ ) and energy efficiency of the existing power distribution systems. $M L I$ gives an estimate of additional load as a factor of the existing load that may be connected at the candidate node before reaching the system voltage collapse (Venkatash et al., 2004; Augugliaro et al., 2005). The value of $M L I$ computed is a function of source voltage or sending end node voltage provided that both voltages remain constant, otherwise it has no significance. PLI is the normalized value of loss reduction, obtained through capacitor placement at each node independently, in [0 1] range. It is calculated as a ratio of the difference between the loss reduction corresponding to candidate node and minimum loss reduction to that of the difference of maximum \& minimum loss reduction.

Depending upon the active and reactive power characteristics, the electrical loads connected to low voltage distribution systems, can be categorised into different load models (Haque et al., 1996). The MLI and PLI for these load models vary with optimal capacitor placement. This is due to the dependency of the load profile on system voltage and frequency deviations. Further, in low voltage distribution systems, the frequency deviations are insignificant. Therefore, in this paper voltage dependent load models are considered, as they improve the quality of all subsequent studies and results (Satyanarayana et al., 2007).

This paper is organized as follows. The smart distribution system operation and its requirements are discussed in section 2 . The maximum loadability limit of radial distribution systems is discussed in section 3 . The mathematical formulation of capacitor placement is described in section 4. The solution techniques of capacitor placement are discussed in section 5. The network considered is analyzed for different load models and the results are presented in section 6.

\section{Smart distribution systems operation and requirements}

A distribution system is a complex network, and the designed configuration has direct bearing on its operation and performance (Fan et al., 2009; Heydt, 2010b; Rogers et al., 2010). Distribution systems act as mediator between generation and consumption, and usually operate on the verge of its loadability limit, so as to supply as many consumers as possible. Therefore, under critical loading condition, the chances of voltage collapse in the area with high load and low voltage profile increases. In most cases, the incidence of unexpected voltage collapse has been experienced due to rapid growth in power demands of certain industrial loads (Satyanarayana et al., 2003; Venkatash et al., 2004). When such collapse occurs, some industrial loads are disconnected through automatic cut-off switches resulting in severe interruptions. The smart distribution systems predict the critical loading conditions and take the preventive measures in advance (Smallwood et al, 2010d).

Operation and evaluation of distribution systems may be divided into voltage regulation, reliability/availability, power quality, operation under faulted conditions, loadability and energy efficiency (Venkata et al., 2004). The smart distribution systems reconfigure the network, under critical loading condition, by incorporating soft computing or index based techniques for optimization function. Further, to enhance the energy efficiency and loadability limit, the reconfigured network operation is optimized by integrating a wide variety of distributed resources (i.e. active and reactive power injection locally). The reactive power management play significant role in optimal operation by improving the system performance. The smart distribution system often accomplishes it with optimal capacitor placement.

The size and location of capacitor in optimization function is associated with reactive components of branch current (Haque, 1999). In complex distribution systems the calculation of size and location is cumbersome. Therefore, the smart distribution systems require an algorithm, based upon solution techniques, which is computationally efficient and numerically robust, to provide better services to electric consumers through optimal operation. To find the optimal size and location of capacitor different solution techniques have been proposed earlier. Forward-Backward sweep or ladder iteration method described in (Satyanarayana et al., 2003; Haque, 1999; Etemadi et al., 2008) is used in this paper, but after including the constraints for taking care of critical compensation. It is simple, easy to implement and reliable for smart distribution system operation and control, and for planning and optimization.

\section{Maximum loadability limit of radial distribution systems}

The smart distribution systems reconfigure the network during steady state operation for load balancing (Baran and Wu, 1989b) to improve maximum loadability limit (Venkatash et al., 2004). The reconfigured network further changes its stability limits as well as the capacitor placement. The capacitor placement is described in section 4 and 5 , and to obtain stability limits, an equivalent network is considered between two nodes as shown in Figure1.

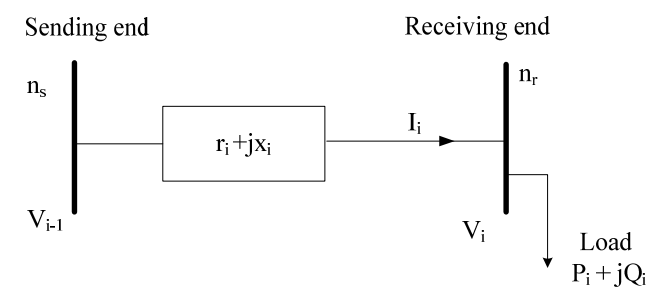


Figure 1. Single line representation of radial distribution system

The phasor diagram of equivalent radial distribution system between two nodes is shown in Figure 2.

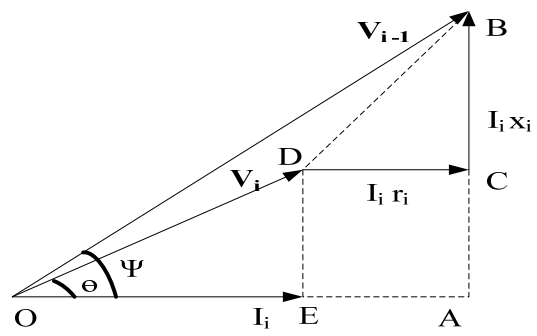

Figure 2. Phasor diagram of equivalent distribution system

From the phasor diagram,

$$
\begin{aligned}
O A & =V_{i-1} \cos \psi=V_{i} \cos \theta+I_{i} r_{i} \\
A B & =V_{i-1} \sin \psi=V_{i} \sin \theta+I_{i} x_{i} \\
V_{i-1}^{2} & =O A^{2}+A B^{2}=O B^{2} \\
& =\left(V_{i} \cos \theta+I_{i} r_{i}\right)^{2}+\left(V_{i} \sin \theta+I_{i} x_{i}\right)^{2}
\end{aligned}
$$

Solving the above equation

$$
V_{i-1}^{2}=V_{i}^{2}+2 r_{i} P_{i}+2 x_{i} Q_{i}+\left(r_{i}^{2}+x_{i}^{2}\right)\left[\frac{P_{i}^{2}+Q_{i}^{2}}{V_{i}^{2}}\right]
$$

where

$$
\begin{aligned}
P_{i} & =V_{i} I_{i} \cos \theta ; \\
Q_{i} & =V_{i} I_{i} \sin \theta ; \\
I_{i} & =\frac{\left(P_{i}^{2}+Q_{i}^{2}\right)^{1 / 2}}{V_{i}} .
\end{aligned}
$$

Re-arranging the above equations, we get

$V_{i-1}^{2}=V_{i}^{2}+2 r_{i} P_{i}+2 x_{i} Q_{i}+r_{i}^{2} \cos ^{2} \theta I_{i}^{2}\left(1+\tan ^{2} \theta\right)+x_{i}^{2} \cos ^{2} \theta I_{i}^{2}\left(1+\tan ^{2} \theta\right)$

Further re-arranging, as in equation (5) in terms of line parameters and writing in generalized form with respect to the $\mathrm{i}^{\text {th }}$ node, for the network having 'n' no. of nodes, the receiving end node voltage equation is obtained as under:

$V_{i}^{2}=\frac{V_{i-1}^{2}}{2}-\left(r_{i} P_{i}+x_{i} Q_{i}\right) \pm\left[\left\{\frac{V_{i-1}^{2}}{2}-\left(r_{i} P_{i}+x_{i} Q_{i}\right)\right\}^{2}-\left(r_{i}^{2}+x_{i}^{2}\right)\left(P_{i}^{2}+Q_{i}^{2}\right)\right]^{1 / 2}=X \pm Y$

Here,

$X=\frac{V_{i-1}^{2}}{2}-\left(r_{i} P_{i}+x_{i} Q_{i}\right) \quad$ and

$Y=\left[\left\{\frac{V_{i-1}^{2}}{2}-\left(r_{i} P_{i}+x_{i} Q_{i}\right)\right\}^{2}-\left(r_{i}^{2}+x_{i}^{2}\right)\left(P_{i}^{2}+Q_{i}^{2}\right)\right]^{1 / 2}$

As in equation (6) mathematically the voltage solution does not exist when the term $\mathrm{Y}^{2}$ becomes negative. Therefore the solution exists when,

$$
\left\{\frac{V_{i-1}^{2}}{2}-\left(r_{i} P_{i}+x_{i} Q_{i}\right)\right\}^{2}-\left(r_{i}^{2}+x_{i}^{2}\right)\left(P_{i}^{2}+Q_{i}^{2}\right) \geq 0
$$

The possible solution, as in equation (7) at particular load defines loadability limit at that node. In order to determine the maximum loadability, the existing load $\left(P_{i}+j Q_{i}\right)$ is replaced by the term $\left\{M L I_{i} *\left(P_{i}+j Q_{i}\right)\right\}$ while the load power factor is assumed constant. Further, modifying, as in equation (7) as quadratic equation by equating it to zero, the $M L I_{i}$ is calculated as under:

$$
M L I_{i}=\frac{V_{i-1}^{2}\left[-\left(r_{i} P_{i}+x_{i} Q_{i}\right)+\sqrt{\left(r_{i}^{2}+x_{i}^{2}\right)\left(P_{i}^{2}+Q_{i}^{2}\right)}\right]}{2\left(x_{i} P_{i}+r_{i} Q_{i}\right)^{2}}
$$


As in equation (8), the $M L I$ at different loads can be obtained. To illustrate the effect of additional loadability on $M L I$ a lossy distribution system is considered. The sending end voltage, load power factor, the line resistance and reactance is assumed to be $|1.0|$ p.u, $0.8,2.8 \Omega$ and $2.2 \Omega$ respectively. The value of $M L I$ is evaluated for various values of power flow through the line and the results in Table 1, for constant power load, show that it decreases as the loading of distribution system is increased. The value of MLI reaches to ' 1 ', indicating that additional load leads to voltage collapse. The network loadability limit is found to be 8.496MVA. The fourth column gives the additional load, the difference of loadability limit i.e. 8.496 and MVA load, which can be connected to the respective node before the system voltage collapse.

Table 1. Effect of additional load on loadability limit

\begin{tabular}{|l|l|l|c|}
\hline $\begin{array}{l}M V A \\
\text { Load }\end{array}$ & $\begin{array}{l}\text { Voltage at node } \\
\text { ' } i \text { (p.u.) }\end{array}$ & $M L I_{i}$ & $\begin{array}{l}\text { Additional } \\
\text { Load (MVA) }\end{array}$ \\
\hline 2.5 & 0.9201 & 3.3984 & 5.996 \\
\hline 3.0 & 0.9022 & 2.8320 & 5.496 \\
\hline 3.5 & 0.8834 & 2.4275 & 4.996 \\
\hline 4.0 & 0.8637 & 2.1240 & 4.496 \\
\hline 4.5 & 0.8429 & 1.8880 & 3.996 \\
\hline 5.0 & 0.8208 & 1.6992 & 3.496 \\
\hline 5.5 & 0.7969 & 1.5447 & 2.996 \\
\hline 6.0 & 0.7710 & 1.4160 & 2.496 \\
\hline 6.5 & 0.7424 & 1.3071 & 1.996 \\
\hline 7.0 & 0.7098 & 1.2137 & 1.496 \\
\hline 7.5 & 0.6712 & 1.1328 & 0.996 \\
\hline 8.0 & 0.6209 & 1.0620 & 0.496 \\
\hline 8.496 & 0.5019 & 1.0000 & 0.000 \\
\hline 8.5 & No solution & 0.9995 & -0.039 \\
\hline
\end{tabular}

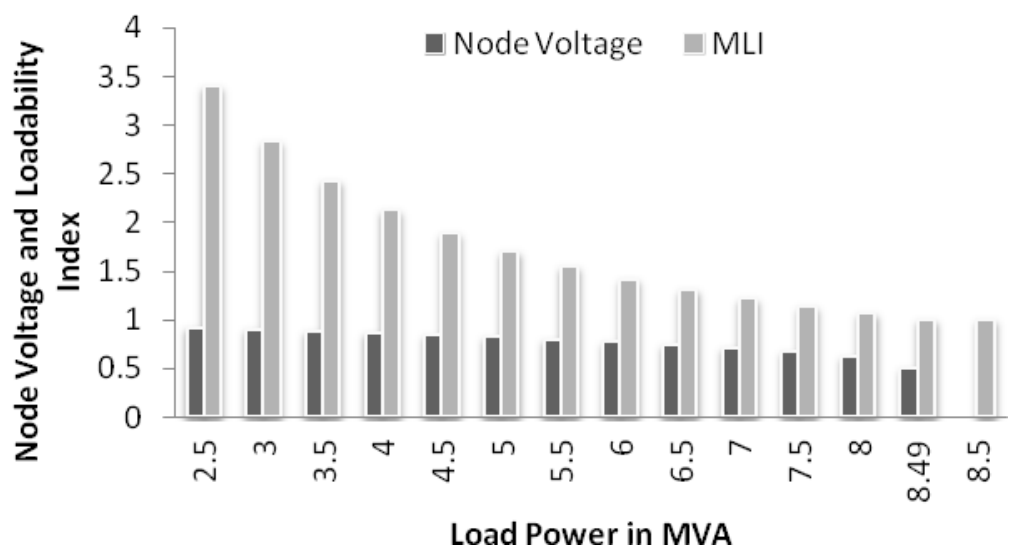

Figure 3. Node voltage and $M L I$ variation with receiving end load

Figure 3 shows that the slope of the $M L I$ graph is exponentially decaying with the linear variation in receiving end node voltage and load. The small variation in load after 8.496MVA leads to sudden shutdown of the system due to voltage collapse. It results in the severe interruptions while supplying power. Therefore, to operate the system under such critical loading conditions, especially when power demand is growing, the loadability limit has to improve. The optimal capacitor placement improves the maximum loadability limit by locally supplying reactive power demand and reducing the line power loss. The effect of capacitor placement on $M L I$ is discussed in section 4 under critical compensation.

\section{Mathematical formulations for capacitor placement}

The problem of optimal capacitor placement requires determination of the location, sizes and number of capacitors to be installed, subject to the operational constraints, in a distribution system to achieve the maximum benefits.

Mathematically, the problem is stated as: 
Maximize loadability by Improving \{minimum of $M L I_{i}$ \}

and

Maximize loss reduction by Capacitor placement $\left\{k V A r_{\text {capacitor }, i} \leq k V A r_{\text {basecase }, i\}}\right.$.

Subject to:

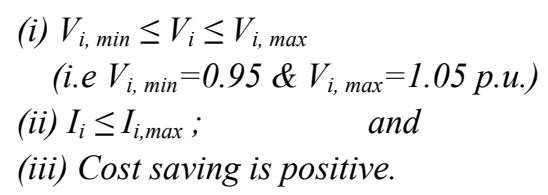

Where, ' $i$ ' varies from ' 1 ' to ' $n$ ' and ' $n$ ' is the no. of nodes.

\subsection{Calculation of Capacitor Size}

The total active power loss for a distribution system with branches is given by,

$$
T P_{L}=\sum_{i=1}^{n} I_{i}^{2} r_{i}
$$

Where, $I_{i}$ and $r_{i}$ are the current magnitude and resistance respectively of the branch ' $i$ '. Separating the real and reactive components of current the power loss can be expressed as:

$$
T P_{L}=\sum_{i=1}^{n} I_{a i}^{2} r_{i}+\sum_{i=1}^{n} I_{r i}^{2} r_{i}
$$

Therefore, $T P_{L}=T P_{L a}+T P_{L r}$

Where, $T P_{L a}$ is power loss due to active components of current and $T P_{L r}$ is power loss due to reactive components of current. The placement of the capacitor is such that the system loss reduction is maximized and the mathematical equations are obtained as follows:

If a capacitor of current $I_{c k}$ is placed at a node $k$, the total real power loss of the system is

$T P_{L}=\sum_{i=b(j)}^{k}\left(I_{r i}+I_{c k}\right)^{2} r_{i}+\sum_{i \neq b(j)}^{n} I_{r i}^{2} r_{i}+\sum_{i=1}^{n} I_{a i}^{2} r_{i}$

Here ' $b$ ' is the branch segments in radial path from source to candidate nodes. Subtracting, as in equation (11) from equation (10), the loss reduction $\triangle T P_{L k}$ can be expressed as:

$$
\Delta T P_{L}=-2 I_{c k} \sum_{i=b(j)}^{k} I_{r i} r_{i}-I_{c k}^{2} \sum_{i=b(j)}^{k} r_{i}
$$

The capacitor current $I_{c k}$ that provides the maximum loss saving can be obtained from,

$$
\frac{\delta\left(\Delta T P_{L k}\right)}{\delta I_{c k}}=-2\left(\sum_{i=b(j)}^{k} I_{r i} r_{i}+I_{c k} \sum_{i=b(j)}^{k} r_{i}\right)=0
$$

Thus, the capacitor current for maximum loss saving is,

$$
I_{c k}=-\left(\frac{\sum_{i=b(j)}^{k} I_{r i} r_{i}}{\left.\sum_{i=b(j)}^{k} r_{i}\right)}\right)
$$

It is assumed that there is no significant improvement in the node voltage $V_{k}$ after capacitor placement, due to change in active component of load current, at respective nodes. Therefore, the size of capacitor at candidate node can be calculated as:

$$
Q_{c k}=I_{c k} V_{k}
$$

The size of capacitor calculated, as in equation (15), may differ at each node. The placement of these sizes of capacitor at respective node does not guarantee to improve the required parameters uniformly. Therefore, a unique technique is required while selecting the candidate node for final placement. The next part of this section describes the effect of critical compensation on power loss, and load models and power loss index for final selection of the capacitor size.

\subsection{Critical Compensation}

In a radial distribution system optimal capacitor placement depends upon reactive components of branch current as described above. Therefore, the size of capacitor, as in equation (15) is always higher than the total reactive power flow at respective node, except the node next to the source in radial path, in first placement. In the subsequent placement the effect of reactive components of current in radial path decreases significantly. It makes the part of distribution system highly compensated and causes the extra power loss in the system. To avoid partial over compensation of the system a technique considering critical compensation for optimal capacitor placement is presented in this paper.

To illustrate the effect of critical compensation, a distribution system is considered operating at its maximum loadability limit as shown in Figure 1. It is considered with same line parameters. Table 2 shows the variations of $M L I$ and power loss with capacitor 
placement. The improvement in power loss reduction and $M L I$ with capacitor placement is noticed before critical compensation. At critical compensation (i.e. 5.5MVAr) the power loss is minimum (i.e. 0.0134 p.u.), whereas further placement improves the node voltage and $M L I$ but raises the power loss. The sample network considered is having only one receiving end node and the capacitor size cannot be more than the reactive power at that node in order to avoid over compensation. Therefore, due to the line reactance, the size of capacitor is marginally higher than the load reactive power for maximum loss reduction.

Table 2. $M L I$ and loss variation by capacitor placement

\begin{tabular}{|c|l|l|l|}
\hline $\begin{array}{l}Q_{c k} \\
\text { (MVAr) }\end{array}$ & $\begin{array}{l}V_{i} \\
\text { (p.u) }\end{array}$ & $M L I_{i}$ & $T P_{L}$ (p.u) \\
\hline 0.0 & 0.5019 & 1.0000 & 0.0333 \\
\hline 1.5 & 0.6615 & 1.1136 & 0.0207 \\
\hline 2.5 & 0.7063 & 1.1943 & 0.0173 \\
\hline 3.5 & 0.7421 & 1.2762 & 0.0152 \\
\hline 4.5 & 0.7721 & 1.3552 & 0.0139 \\
\hline 5.5 & $\mathbf{0 . 7 9 8 2}$ & $\mathbf{1 . 4 2 7 2}$ & $\mathbf{0 . 0 1 3 4}$ \\
\hline 6.5 & 0.8213 & 1.4880 & 0.0136 \\
\hline 7.0 & 0.8422 & 1.5349 & 0.0143 \\
\hline 8.5 & 0.8612 & 1.5669 & 0.0155 \\
\hline 9.5 & 0.8686 & 1.5845 & 0.0173 \\
\hline
\end{tabular}

\subsection{Load Models}

The smart distribution system supply controlled power to residential, commercial and industrial loads. In practical situation, loads are not explicitly of any one type; rather combination of these may be seen depending on the requirement of area being supplied. Usually, these loads are voltage dependent and they are modelled as Constant Power $(C P)$, Constant Current $(C C)$, Constant Impedance $(C I)$, Exponential $(X P)$ and Composite $(C M)$ loads (Haque, 1999). To quantify the effect of various load models on optimal capacitor placement, a 15-node radial distribution system is considered shown in Figure 4. The different load models and their exponent are tabulated below:

Table 3. Load models and their exponents

\begin{tabular}{|l|c|c|}
\hline Load Models & $\alpha$ & $\beta$ \\
\hline Constant power & 0.00 & 0.00 \\
Constant current & 1.00 & 1.00 \\
Constant impedance & 2.00 & 2.00 \\
Exponential & 1.38 & 3.22 \\
Composite & --- & --- \\
\hline
\end{tabular}

A composite load is the combination of all the above load models. In this paper it consists of $40 \%$ constant power, $30 \%$ constant current, $20 \%$ constant impedance \& $10 \%$ exponential loads. The load models at respective node can be mathematically expressed as,

$$
\begin{aligned}
P_{s i} & =\sum_{i=1}^{n} P_{i} V_{i}^{\alpha} \\
Q_{s i} & =\sum_{i=1}^{n} Q_{i} V_{i}^{\beta}
\end{aligned}
$$

And, the total active power loss is given by,

$$
T P_{L}=\sum_{i=1}^{n} \frac{\left(P_{s i}^{2}+Q_{s i}^{2}\right)}{V_{i}^{2}} r_{i}
$$

During investigations the comparison of constant power load model with the existing results are emphasized. While investigating the system with constant current load model, it is assumed to be supplying constant current load only and similarly for other loads.

\subsection{Power Loss Index}

Table 2 shows that the capacitor placement improves the node voltage, by changing the resultant power flow in the system, and also reduces power loss. Therefore, the network when compensated by $Q_{c k}$ (i.e. optimal capacitor size calculated, as in (15) at the respective nodes) releases the feeder kVAr capacity and reduces resultant power loss. The power loss reduction in the compensated network varies from minimum to maximum value, and is calculated as under: 


$$
\Delta T P_{L i}=T P_{L i}(\text { Base })=T P_{L i}\left(\text { compensated }, Q_{c k}\right)
$$

It may also vary for actual and standard values of capacitor placement. The standard value capacitors are available in size of 150 , $300,450,600,900$ and 1200kVAr. In actual system, the combinations of fixed and switched capacitors are used. Based upon the loss reduction, the power loss index PLI (i.e. normalized value of loss reduction in $\left(\begin{array}{ll}0 & 1\end{array}\right)$ range) can be obtained, in respect to the candidate node, as under:

$$
P L I_{i}=\frac{\Delta T P_{L i}-\Delta T P_{L \min }}{\Delta T P_{L \max }-\Delta T P_{L \text { min }}}
$$

The reduction in active power loss from base network describes the selection criterion for optimal capacitor placement using power loss index. The node having the maximum PLI indicates the highest priority of getting selected as the candidate node for capacitor placement.

\section{Solution technique for optimal capacitor placement}

The computational steps involved in the solution technique for identifications of candidate node for optimal capacitor placement in a radial distribution system, based upon the mathematical formulation presented in sections 3 and 4, are as follows:

Step1: Run the load flow program by assuming flat voltage profile as 1p.u. and line power loss zero initially, and setting the convergence criterion (selected as $\varepsilon=0.0001$ in this paper).

Step2: Compute the node voltage, MLI, capacitor size at each node and power loss, as in (6, 8, 15 and 18) for base network.

Step3: Compute power loss by placing the capacitor \& PLI corresponding to each node, as in (20). Select the node with maximum PLI as candidate node.

Step4: Repeat Step 1 to Step 3 to get the next candidate node for placement by fixing the capacitor size at candidate node obtained in Step 3.

Step5: Ensure that none of the candidate node is over compensated from its optimum value. If it is, reduce the same and repeat the whole process until it is found that voltage is in limit and no significant cost saving can be achieved by the further placements.

\section{Test results and discussion of sample case}

The sample system under study is a $11 \mathrm{kV}$, IEEE15-node radial distribution network as shown in Figure 4 . The data of the system are obtained from Satyanarayana et al. (2003) and Haque (1999), and the substation voltage is maintained at |1.0| p.u. The network is analyzed for different load models discussed above. The loading is considered fixed, and the following assumptions are made: a) The radial distribution system is balanced and can be represented by a single line diagram (b) At distribution level of voltage the shunt capacitance is negligible, and if any, is considered as load (c) The substation feeder is capable of supplying the load demand.

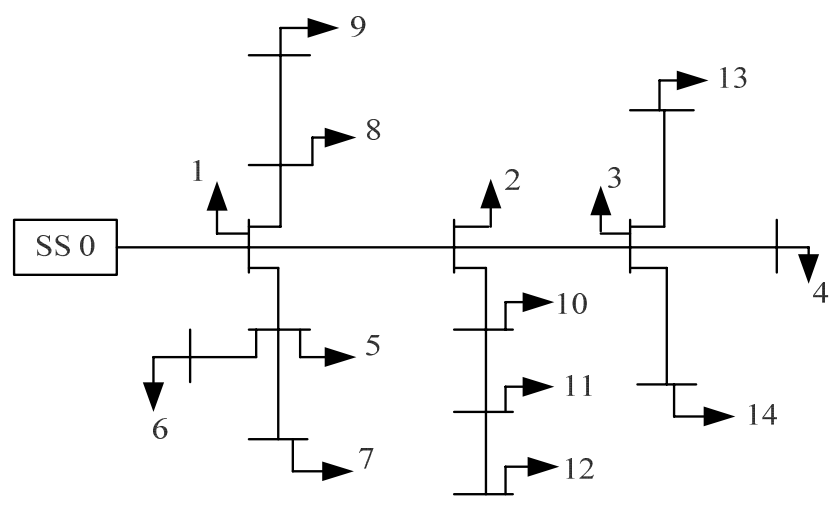

Figure 4. A IEEE 15-Nodes radial distribution system

To find out the optimum location, for first placement, network is considered with constant power load model. From the load flow solution the total power loss, for base network, associated with active and reactive components of currents is found $61.78 \mathrm{~kW}$. The reactive power and optimum capacitor size at respective nodes also obtained and tabulated in Table 4. 
Table 4. PLI and loss variation with capacitor placement

\begin{tabular}{|l|l|l|l|l|l|}
\hline$n$ & $\begin{array}{l}Q_{s i} \\
(\mathrm{kVAr})\end{array}$ & $\begin{array}{l}Q_{c k}{ }^{*} 10^{3} \\
(\mathrm{kVAr})\end{array}$ & $\begin{array}{l}T P_{L} \\
(\mathrm{~kW})\end{array}$ & $\begin{array}{l}\Delta T P_{L} \\
(\mathrm{~kW})\end{array}$ & $P L I$ \\
\hline 1 & 1271.30 & 1.2713 & 41.332 & 20.449 & 0.752 \\
\hline 2 & 737.34 & 1.0134 & 37.103 & 24.677 & 1.000 \\
\hline 3 & 402.45 & 0.8561 & 38.131 & 23.649 & 0.939 \\
\hline 4 & 44.98 & 0.6027 & 44.723 & 17.057 & 0.554 \\
\hline 5 & 357.34 & 0.6677 & 45.324 & 16.456 & 0.519 \\
\hline 6 & 142.80 & 0.5522 & 47.363 & 14.417 & 0.399 \\
\hline 7 & 71.40 & 0.5224 & 48.471 & 13.309 & 0.335 \\
\hline 8 & 116.42 & 0.5785 & 51.222 & 10.558 & 0.174 \\
\hline 9 & 44.98 & 0.4002 & 54.203 & 7.5776 & 0.000 \\
\hline 10 & 259.64 & 0.6958 & 41.706 & 20.075 & 0.730 \\
\hline 11 & 116.43 & 0.4843 & 46.464 & 15.316 & 0.452 \\
\hline 12 & 44.98 & 0.3831 & 49.332 & 12.449 & 0.284 \\
\hline 13 & 71.40 & 0.5420 & 45.964 & 15.817 & 0.481 \\
\hline 14 & 142.80 & 0.6673 & 42.239 & 19.542 & 0.699 \\
\hline
\end{tabular}

Further, compensate the network with optimal sizes exclusively. The maximum power loss reduction, and hence $P L I$, is noticed when network is compensated with $1013.4 \mathrm{kVAr}$ at $2^{\text {nd }}$ node. Therefore, $2^{\text {nd }}$ node is selected as the candidate node, for this placement. The variations in capacitor size and PLI obtained at different nodes are presented in Figure 5.

In first placement, it is noticed that optimal capacitor size is $1013.4 \mathrm{kVAr}$ and the reactive power flow is $737.34 \mathrm{kVAr}$ at $2^{\text {rd }}$ node, for base network. The optimum size obtained is much higher than the reactive power flow. This is due to the variations in reactive component of line currents in radial path starting from source node to candidate node. In subsequent placement, the maximum

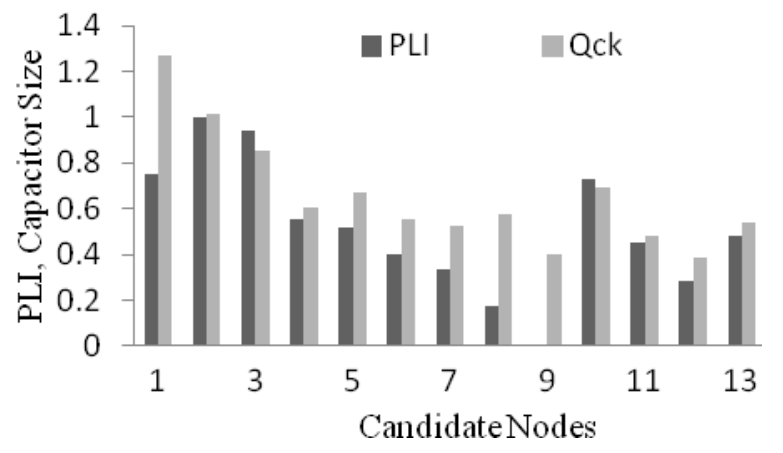

Figure 5. Capacitor size and PLI at candidate node

PLI, and the capacitor value obtained is $319.9 \mathrm{kVAr}$ at $5^{\text {th }}$ node. It is less than the reactive power flow i.e. $357.34 \mathrm{kVAr}$ at respective node. This is due to the effect of reactive component of current, in partial radial path, mostly considered in previous placement. As a result, the placement of optimal capacitor at $5^{\text {th }}$ node causes the $2^{\text {rd }}$ node over compensated from its optimum value by 165.2kVAr. Therefore, to avoid the over compensation due to subsequent placement it is reduced by this value. On reduction of capacitor size placed, the maximum $P L I$ and the optimal capacitor value obtained is $110.4 \mathrm{kVAr}$ at $11^{\text {th }}$ node. However, placement of capacitor of value $110.4 \mathrm{kVAR}$ at $11^{\text {th }}$ node causes over compensation at $2^{\text {rd }}$ node from its optimum value by $111.3 \mathrm{kVAr}$. Thus, it is reduced and the process is repeated for subsequent placement till all the compensated nodes do not have its value less than or equal to base network reactive power flow. The process is also repeated for further studies, for different load models, described in next parts of this section.

The summery of test results for different load models is discussed below:

\subsection{Constant Power Load Model}

Table 5 shows the test results of the constant power load model. The load flow results for base network are shown in column $2^{\text {nd }}$. The column $3^{\text {rd }}$ and $4^{\text {th }}$ shows the test results obtained using existing methods described (Satyanarayana et al., 2003) and (Haque, 1999) respectively. The $3^{\text {nd }}$ column shows the capacitor of $1200 \mathrm{kVAr}$ is required to be placed for maximum loss reduction at nodes $2^{\text {nd }}$ and $5^{\text {th }}$ of value 900 and $300 \mathrm{kVAr}$. The results in column $4^{\text {th }}$ shows the capacitor required to be placed at node $2^{\text {nd }}$ and 
$5^{\text {th }}$ of value $805,388 \mathrm{kVAr}$ respectively. It is observed from the test result that the total reactive power requirement of the system is 1308.2kVAr. Therefore, the capacitor size obtained using the methods described (Satyanarayana et al, 2003) and (Haque, 1999) at candidate nodes in subsequent placement causes partial over compensation.

From the test results shown in Table 5 it can also observed that $\mathrm{P}_{\mathrm{FD}}, \mathrm{Q}_{\mathrm{FD}}$ and $\mathrm{S}_{\mathrm{FC}}$ for base network is $1288.2 \mathrm{~kW}, 1308.2 \mathrm{kVAr}$ and $1836.0 \mathrm{kVA}$ respectively. With the capacitor placement of sizes $736.3,319.9 \& 110.4 \mathrm{kVAr}$ at $2^{\text {nd }}, 5^{\text {th }}$ and $11^{\text {th }}$ nodes, these are reduced to $1258.1 \mathrm{~kW}, 113.5 \mathrm{kVAr}$ and $1263.2 \mathrm{kVA}$ for actual, and $1258.1 \mathrm{~kW}, 80.1 \mathrm{kVAr}$ and $1260.6 \mathrm{kVA}$ for standard values, respectively. The minimum $M L I$ at node $1^{\text {st }}$, minimum voltage at node $13^{\text {th }}$ and the power loss for the base network is 8.9631 , 0.9445 p.u.and $61.78 \mathrm{~kW}$. Whereas, for compensated network with actual and standard values these are improved significantly to $14.5438,0.9695$ p.u. \& $31.71 \mathrm{~kW}$ and $14.7138,0.9714$ p.u. \& $31.67 \mathrm{~kW}$ respectively. The extra improvement in node voltage, $M L I$ and power loss with standard capacitor is due to the assumption made for node voltage in finding the size of capacitor,

Table 5. Test results for constant power load

\begin{tabular}{|c|c|c|c|c|c|}
\hline \multirow[t]{2}{*}{ Parameters } & \multirow{2}{*}{$\begin{array}{l}\text { Base } \\
\text { Value }\end{array}$} & \multirow{2}{*}{$\begin{array}{c}\text { (Satyanarayana } \\
\text { et al., 2003) }\end{array}$} & \multirow{2}{*}{$\begin{array}{c}\text { (Haque, } \\
1999)\end{array}$} & \multicolumn{2}{|c|}{ Proposed } \\
\hline & & & & $Q_{a c t}$ & $Q_{\text {std }}$ \\
\hline$P_{F D}(\mathrm{~kW})$ & 1288.2 & 1259.3 & 1259.0 & 1258.1 & 1258.1 \\
\hline$Q_{F D}(\mathrm{kVAr})$ & 1308.2 & 80.9 & 87.7 & 113.5 & 80.1 \\
\hline$S_{F C}(\mathrm{KVA})$ & 1836.0 & 1261.9 & 1262.1 & 1263.2 & 1260.6 \\
\hline $\begin{aligned} Q_{c k}(\mathrm{kVAr}) \\
\text { at nodes, } \\
\\
(2) \\
(5) \\
(11)\end{aligned}$ & --- & $\begin{array}{c}1200 \\
900 \\
300 \\
---\end{array}$ & $\begin{array}{c}1193 \\
805 \\
388 \\
---\end{array}$ & $\begin{array}{c}1166.6 \\
736.3 \\
319.9 \\
110.4\end{array}$ & $\begin{array}{l}1200 \\
750 \\
300 \\
150\end{array}$ \\
\hline Min. $V_{i}$ (p.u) & 0.9445 & 0.9675 & 0.9666 & 0.9695 & 0.9714 \\
\hline Min. $M L I_{i}$ & 8.963 & 14.696 & 14.665 & 14.544 & 14.713 \\
\hline$T P_{L}(\mathrm{~kW})$ & 61.78 & 32.86 & 32.61 & 31.71 & 31.67 \\
\hline$P_{R D}(\mathrm{~kW})$ & --- & 28.73 & 29.18 & 30.09 & 30.13 \\
\hline$S_{R D}(\mathrm{KVA})$ & --- & 574.14 & 573.94 & 572.77 & 575.38 \\
\hline$N C$ & --- & 7.90 & 7.96 & 8.23 & 8.23 \\
\hline
\end{tabular}

As in equation (15). This would have given the size of capacitor slightly more than the value obtained which further improves the node voltage, and hence reduces the active component of line currents. The last row in Table 5 shows the net cost savings by optimal capacitor placement using methods described in Satyanarayana et al. (2003) and Haque (1999), and the one proposed in the current work. The cost of the capacitor, released power demand, released feeder capacity, cost $/ \mathrm{kWh}$ and the line data for the network considered is taken same. Figure 6 depicts the variation of minimum $M L I$, power losses and net savings by different methods as discussed above. The test results using proposed technique are significantly improved.

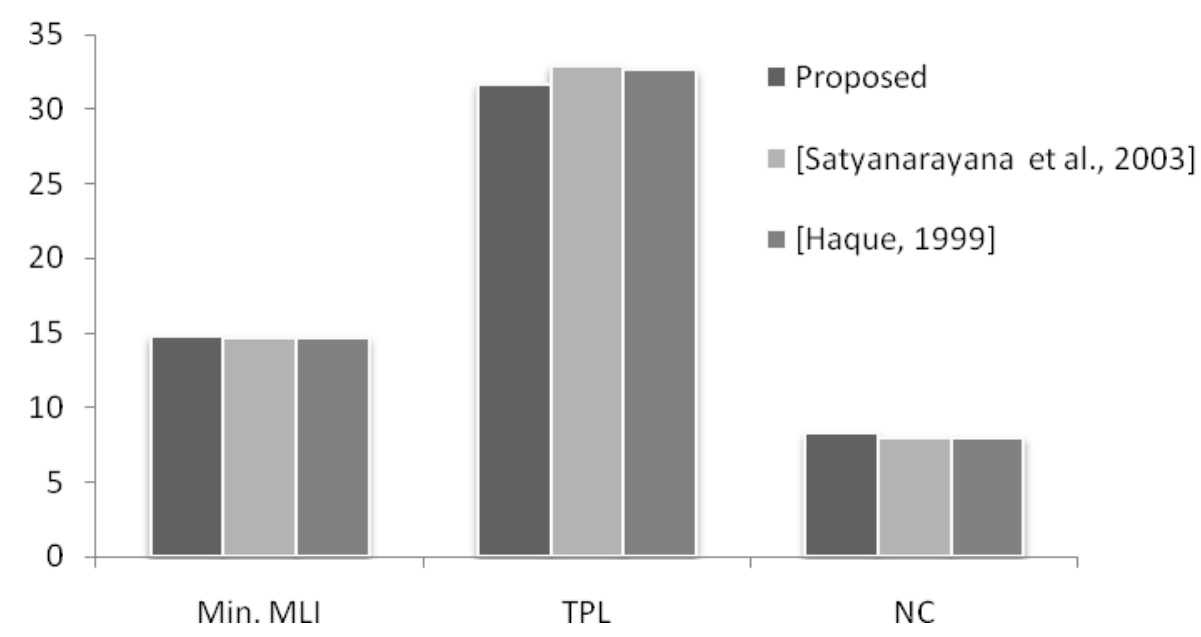

Figure 6. Minimum $M L I$, power loss and net cost saving by different methods 


\subsection{Constant current load model}

Test results for constant current load model are shown in Table 6. The $P_{F D}, Q_{F D}$ and $S_{F C}$ for base network is $1229.0 \mathrm{~kW}$, $1248.3 \mathrm{kVAr}$ and $1751.8 \mathrm{kVA}$ respectively. With the capacitor placement of sizes $733.6,323.4 \& 107.4 \mathrm{kVAr}$ at $2^{\text {nd }}, 5^{\text {th }}$ and $11^{\text {th }}$ nodes, these are reduced to $1226.1 .1 \mathrm{~kW}, 108.9 \mathrm{kVAr}$ and $1230.9 \mathrm{kVA}$ for actual and $1227.0 \mathrm{~kW}, 74.3 \mathrm{kVAr}$ and $1229.3 \mathrm{kVA}$ for standard values respectively. The minimum MLI at node $1^{\text {st }}$, minimum voltage at node $13^{\text {th }}$ and the power loss for the base network is $9.3812,0.9472$ p.u.and $56.13 \mathrm{~kW}$. Whereas, for compensated network with actual and standard values these are improved to 14.9253 , 0.9703p.u. \& $30.09 \mathrm{~kW}$, and $15.0990,0.9722$ p.u. \& $30.10 \mathrm{~kW}$ respectively. With standard capacitor placement, the voltage dependent nature of load draws more power from the source due to improvement in voltage profile. This causes more power loss, in context to constant power load model, in the network. However, the overall significant improvements in performance result in net cost saving.

Table 6. Test results for constant current load

\begin{tabular}{|l|l|l|l|}
\hline Parameters & $\begin{array}{l}\text { Base } \\
\text { Case }\end{array}$ & $\begin{array}{l}\text { With } \\
Q_{\text {act }}\end{array}$ & $\begin{array}{l}\text { With } \\
Q_{\text {std }}\end{array}$ \\
\hline$P_{F D}(\mathrm{~kW})$ & 1229.0 & 1226.1 & 1227.0 \\
\hline$Q_{F D}(\mathrm{kVAr})$ & 1248.3 & 108.9 & 74.3 \\
\hline$S_{F C}(\mathrm{KVA})$ & 1751.8 & 1230.9 & 1229.3 \\
\hline$Q_{c k}(\mathrm{kVAr})$ & --- & 1163.7 & 1200 \\
at nodes, (2) & & 733.6 & 600 \\
$(5)$ & & 323.4 & 300 \\
$(11)$ & & 107.4 & 150 \\
\hline Min. $V_{i}$ (p.u) & 0.9472 & 0.9703 & 0.9722 \\
\hline Min. $M L I_{i}$ & 9.3812 & 14.9253 & 15.0990 \\
\hline$T P_{L}$ (kW) & 56.13 & 30.09 & 30.10 \\
\hline$P_{R D}(\mathrm{~kW})$ & --- & 2.89 & 1.97 \\
\hline$S_{R D}(\mathrm{KVA})$ & --- & 520.87 & 522.53 \\
\hline$N C$ & --- & 6.61 & 6.58 \\
\hline
\end{tabular}

\subsection{Constant impedance load model}

Test results for constant impedance load model are shown in Table 7. The $P_{F D}, Q_{F D}$ and $S_{F C}$ for base network are $1177.5 \mathrm{~kW}$, $1196.3 \mathrm{kVAr}$ and $1678.6 \mathrm{kVA}$ respectively. The capacitor placement improves voltage profile, and hence the performance of voltage dependent load models. The improved profiles of load draw active power of $1196.5 \mathrm{~kW}$ and $1198.4 \mathrm{~kW}$, enhanced by $19.04 \mathrm{~kW}$ and $20.92 \mathrm{~kW}$ for actual and standard value placements, respectively. However, the overall system performance improves by reducing power loss, reactive power flow, and improving minimum MLI from base network, is noticed.

Table 7. Test results for constant impedance load

\begin{tabular}{|l|l|l|l|}
\hline Parameters & $\begin{array}{l}\text { Base } \\
\text { Case }\end{array}$ & $\begin{array}{l}\text { With } \\
Q_{a c t}\end{array}$ & $\begin{array}{l}\text { With } \\
Q_{\text {std }}\end{array}$ \\
\hline $\mathrm{P}_{\mathrm{FD}}(\mathrm{kW})$ & 1177.5 & 1196.5 & 1198.4 \\
\hline$Q_{F D}(\mathrm{kVAr})$ & 1196.3 & 105.3 & 68.9 \\
\hline$S_{F C}(\mathrm{KVA})$ & 1678.6 & 1201.2 & 1200.4 \\
\hline$Q_{c k}(\mathrm{kVAr})$ & --- & 1163.6 & 1200 \\
at nodes, (2) & & 734.4 & 750 \\
$(5)$ & & 325.2 & 300 \\
\multicolumn{1}{c}{$(11)$} & & 101.9 & 150 \\
\hline Min. $V_{i}$ (p.u) & 0.9496 & 0.9709 & 0.9729 \\
\hline Min. $M L I_{i}$ & 9.7787 & 15.2919 & 15.4723 \\
\hline$T P_{L}(\mathrm{~kW})$ & 51.44 & 28.64 & 28.69 \\
\hline$P_{R D}(\mathrm{~kW})$ & --- & -19.04 & -20.92 \\
\hline$S_{R D}(\mathrm{KVA})$ & --- & 477.43 & 478.20 \\
\hline$N C$ & --- & 5.31 & 5.25 \\
\hline
\end{tabular}




\subsection{Exponential load model}

Similarly, the constant current and impedance load models the performance of these load models depends upon its voltage profile. The test results in Table 8 show that $\mathrm{P}_{\mathrm{FD}}, \mathrm{Q}_{\mathrm{FD}}$ and $\mathrm{S}_{\mathrm{FC}}$ for base network is $1207.3 \mathrm{~kW}, 1138.6 \mathrm{kVAr}$ and 1659.5kVA respectively. Due to the voltage dependency the improved load profile draw more active power of $7.26 \mathrm{~kW}$ and $8.65 \mathrm{~kW}$ for actual and standard value placements respectively. However, the improvement in loss reduction, reactive power flow, and minimum MLI from base network makes the capacitor placement cost-effective.

Table 8. Test results for exponential load

\begin{tabular}{|l|l|l|l|}
\hline Parameters & $\begin{array}{l}\text { Base } \\
\text { Case }\end{array}$ & $\begin{array}{l}\text { With } \\
Q_{a c t}\end{array}$ & $\begin{array}{l}\text { With } \\
Q_{s t d}\end{array}$ \\
\hline$P_{F D}(\mathrm{~kW})$ & 1207.3 & 1214.6 & 1215.9 \\
\hline$Q_{F D}(\mathrm{kVAr})$ & $1138 . .6$ & 103.3 & 64.9 \\
\hline$S_{F C}(\mathrm{KVA})$ & 1659.5 & 1218.9 & 1217.7 \\
\hline$Q_{c k}(\mathrm{kVAr})$ & --- & 1154.6 & 1200 \\
at nodes, (2) & & 731.3 & 750 \\
$(5)$ & & 326.2 & 300 \\
$(11)$ & & 100.5 & 150 \\
\hline Min. $V_{i}$ (p.u) & 0.9501 & 0.9705 & 0.9726 \\
\hline Min. $M L I_{i}$ & 9.8882 & 15.0889 & 15.2807 \\
\hline$T P_{L}(\mathrm{~kW})$ & 50.25 & 29.30 & 29.34 \\
\hline$P_{R D}(\mathrm{~kW})$ & --- & -7.26 & -8.65 \\
\hline$S_{R D}(\mathrm{KVA})$ & --- & 440.55 & 441.82 \\
\hline$N C$ & --- & 5.05 & 4.99 \\
\hline
\end{tabular}

\subsection{Composite load model}

Composite load model is the combination of all the above load models as discussed earlier. Though, it may be of any combination, in the analysis constant load model contributes most. However, unlike the constant current and impedance load models the performance of composite load model partially depends upon its voltage profile. The test results in Table 9 show that $\mathrm{P}_{\mathrm{FD}}, \mathrm{Q}_{\mathrm{FD}}$ and $\mathrm{S}_{\mathrm{FC}}$ for base network is $1238.5 \mathrm{~kW}, 1248.76 \mathrm{kVAr}$ and $1758.7 \mathrm{kVA}$ respectively. With the capacitor placement of sizes $733.8,323.3 \& 107.3 \mathrm{kVAr}$ a $2^{\text {nd }}, 5^{\text {th }}$ and $11^{\text {th }}$ nodes, the voltage profile and minimum $M L I$ improves from base network. The improved system voltage profile tends to reduce the power loss, and released the power demand and feeder capacity by $7.16 \mathrm{~kW}$, $522.54 \mathrm{kVA}$, and $6.39 \mathrm{~kW}, 524.35 \mathrm{kVA}$ for actual and standard value placement respectively. The improvement in loss reduction, reactive power flow and minimum $M L I$ makes the capacitor placement cost-effective. In this case the net cost saving is distinctly higher than other load models except constant power load.

Table 9. Test results for composite power load

\begin{tabular}{|l|l|l|l|}
\hline Parameters & $\begin{array}{l}\text { Base } \\
\text { Case }\end{array}$ & $\begin{array}{l}\text { With } \\
Q_{a c t}\end{array}$ & $\begin{array}{l}\text { With } \\
Q_{\text {std }}\end{array}$ \\
\hline$P_{F D}(\mathrm{~kW})$ & 1238.5 & 1231.3 & 1232.1 \\
\hline$Q_{F D}(\mathrm{kVAr})$ & 1248.7 & 109.1 & 75.5 \\
\hline$S_{F C}(\mathrm{KVA})$ & 1758.7 & 1236.2 & 1234.4 \\
\hline$Q_{c k}(\mathrm{kVAr})$ & --- & 1163.6 & 1200 \\
at nodes, (2) & & 733.8 & 750 \\
$(5)$ & & 323.3 & 300 \\
$(11)$ & & 107.3 & 150 \\
\hline Min. $V_{i}$ (p.u) & 0.9470 & 0.9701 & 0.9721 \\
\hline Min. $M L I_{i}$ & 9.3451 & 14.8644 & 15.0385 \\
\hline$T P_{L}(\mathrm{~kW})$ & 56.58 & 30.33 & 30.33 \\
\hline$P_{R D}(\mathrm{~kW})$ & --- & 7.16 & 6.39 \\
\hline$S_{R D}(\mathrm{KVA})$ & --- & 522.54 & 524.35 \\
\hline$N C$ & --- & 6.76 & 6.73 \\
\hline
\end{tabular}

From the test result it is noticed that the optimal capacitor placement remains no more optimum as the load demand or the load models changes. The network parameters with changed load demand or the load models are re-calculated. Figure 7 depicts the 
variation of $M L I$, power loss and net saving, with standard value capacitor placement, for different load models. It is found that the performance and net saving is remarkably different from those of load models considered so far. Therefore, in power distribution systems the reliability of the results depends upon the load modeling during calculations, because the dynamic load behavior can be the major reason for voltage collapse. The smart capacitor placement avoids the system voltage collapse by improving the maximum loadability limit.

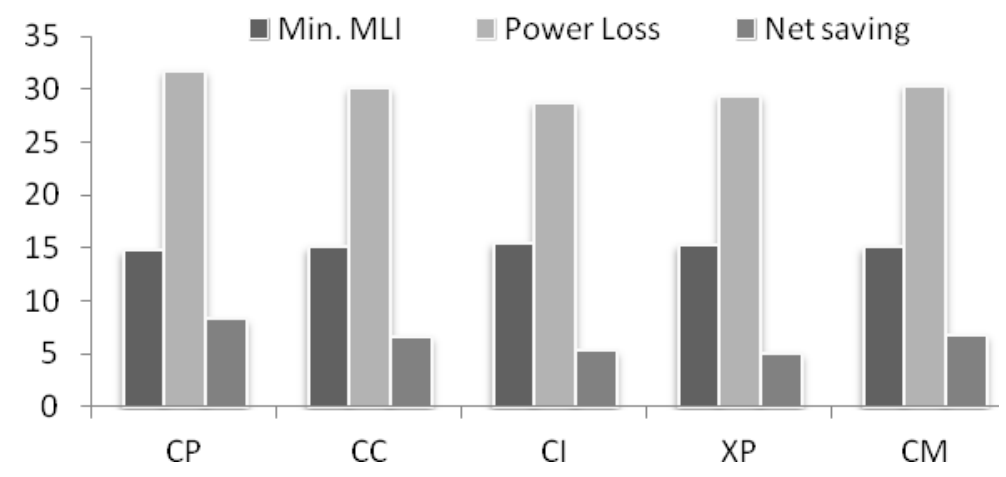

Figure 7. Minimum $M L I$, power loss and net saving for load models

The test results show that the optimum capacitor placement improves minimum voltage, $M L I$ and reduces the power loss. It further improves feeder capacity by releasing $\mathrm{kW}$ and kVA demands, and hence the energy efficiency in distribution systems.

\section{Conclusions}

In determining the optimal size and location of capacitors using conventional method, it is observed that the optimal capacitor placement is most affected by the reactive components of branch current in radial path starting from source to candidate nodes. During investigations for different load models, it is observed that the effect of reactive component of current is maximum in the first placement. It causes over compensation from its optimum value in parts of the system in subsequent placements. Unlike the conventional objective function of optimal capacitor placement which includes the cost of resistive loss, a new objective function for critical compensation is presented in this paper. The solution technique has been developed for critical compensation and demonstrated on an IEEE 15 bus distribution system for different load models. The candidate node is selected based upon the maximum $P L I$ and minimum $M L I$ improved from the base network. The result presented indicates that considerable improvement in power loss reduction, voltage profiles, loadability limit and annual cost saving of the system was observed. It further results in improving the energy efficiency by additional released power demand and feeder capacity, while comparing with the same optimal size of capacitor obtained using existing methods, in radial distribution systems. Further, the design of modern distribution systems is based upon the loadability limit, therefore, the released power demand and feeder capacity may help in improving the system performance to meet present and future load demands.

From the results it is noticed that the dynamic load behavior may affect the loadability limit and energy efficiency in distribution systems during operation. It is, therefore, necessary to improve our knowledge of the load models. The solution technique developed in this paper is only for radial networks with balanced loads. Practical implementation of the capacitor placement technique requires further development for meshed and radial distribution systems, for more specific balanced and unbalanced load models.

\section{Nomenclature}
$\alpha, \beta$
$C P, \quad C C$
$C I, \quad X P$
$C M$
$M L I_{i}$
$N C$
$P_{F D}, Q_{F D}$
$P_{R D}$
$P L I_{i}$
$P_{i}, Q_{i}$
$P_{s i}, Q_{s i}$
$Q_{c k}, Q_{a c t}$,

Voltage exponents of active and reactive loads.

Constant power and current load models.

Constant impedance and exponential load models.

Composite load model.

Maximum loadability index at node $i$.

Net cost saving in Rs/- (Lac.)

Active and reactive power demands.

Released active power demand.

Power loss index at node $i$

Active and reactive load at node ' $i$ ' at nominal voltage of $|1.0|$ p.u.

Active and reactive load beyond node $i$

Optimal size of capacitor at node ' $k$ ', actual and 


$\begin{array}{ll}Q_{s t d} & \text { standard value. } \\ r_{i}, x_{i} & \text { Resistance and reactance of }{ }^{t h} \text {, line. } \\ S_{F C} & \text { KVA capacity of feeder. } \\ S_{R D} & \text { Released feeder capacity. } \\ T P_{L} & \text { Total active power loss. } \\ V_{i}, I_{i} & \text { Voltage and current at } i^{\text {th }} \text { node }\end{array}$

\section{References}

Augugliaro A., Dusonchet L., Favuzza S., Ippolito M. G., and Riva Sanseverino E., 2005. A simple method to assess loadability of radial distribution networks, in Proc. IEEE Power Tech., pp. 1-7.

Baran M.E., and Wu F.F., 1989a. Optimal sizing of capacitor placement in radial distribution system. IEEE Trans. Power Delivery, Vol. 4, No. 2, pp. 735-743.

Baran M.E., and Wu F.F., 1989b. Network reconfiguration in distribution system for loss reduction and load balancing, IEEE Trans. Power Delivery, Vol. 4, No. 2, pp. 1401-1407.

Bhattacharya S.K., and S.K.Goswami., 2009, A new fuzzy based solution of the capacitor placement problem in radial distribution system. Journal on Expert Systems with Applications. Vol. 36, No. 3, pp. 4207-4212.

Chang C.F., 2008, Reconfiguration and capacitor placement for loss reduction of distribution systems by ant colony search algorithm. IEEE Transactions on Power Systems. Vol. 23, No. 4, pp. $1747-1755$.

Etemadi A.H., and Fotuhi-Firuzabad M., 2008. Distribution system reliability enhancement using optimal capacitor placement, IET Journal on Generation, Transmission \& Distribution, Vol. 2, No. 5, pp. 621-631.

Fan J., Borlase S., 2009c. The evolution of distribution, IEEE Power and Energy Magazine, Vol. -7, No. 2, pp. 63-68.

Haghifam M. R., and Malik O.P., 2007. Genetic algorithm-based technique for fixed and switchable capacitors placement in distribution systems with uncertainty and time varying loads, IET Journal Generation, Transmission \& Distribution, Vol. 1, No. 2, pp. 244-252.

Haque M. H., 1996. Load flow solution of distribution system with voltage dependent load model, Taylor \& Francis Journal Electrical Power System, Rec., Vol. 36, pp. 151-156.

Haque M. H., 1999. Capacitor placement in radial distribution systems for loss reduction, in Proc. IEE Generation, Transmission, Distribution, Vol. 146, No. 5, pp. 501-505.

Heydt G.T., 2010. The next generation of power distribution system, IEEE Trans. Smart Grid, Vol. 1, No. 3, pp. 225-235.

Leonardo W., de Oliveira, Sandoval Carneiro Jr., Edimar J. de Oliveira, J.L.R. Pereira, Ivo C. Silva Jr., Jeferson S. Costa., 2010a, Optimal reconfiguration and capacitor allocation in radial distribution systems for energy losses minimization. Elsevier journal on Electrical Power and Energy Systems. Vol. 32, No. 8, pp. 840-848.

Mekhamer S.F., Soliman S.A., Moustafa M A., and El-Hawary M.E., 2003b. Application of fuzzy logic for reactive power compensation of radial distribution feeders. IEEE Trans. Power Systems, Vol. 18, No. 1, pp. 206-213.

Rogers K.M., Klump R., Khurana H., Aquino A.A., Overbye T.J., 2010. An authenticated control framework for distributed voltage support on the smart grid, IEEE Trans. Smart Grid, Vol. 1, No. 1, pp. 40-47.

Smallwood C., and Wennermark J., 2010d. Benefits of distribution automation, IEEE Industry Application Magazine, Vol. 16, No. 1 , pp. 65-73.

Satyanarayana S., Ramana T., Sivanagaraju S., and Rao G.K., 2003. Voltage stability analysis for radial distribution networks with and without compensation, International Journal of Water and Energy, Vol.60, No.1, pp.48-53.

Satyanarayana S., Ramana T., Sivanagaraju S., and Rao G.K., 2007. An efficient load flow solution for radial distribution network including voltage dependent loads models, Journal Electric Power Components and Systems, Vol. 35, No. 5, pp. 539-551.

Venkata S. S., Pahwa A., Brown R. E., and Christie R. D., 2004. What future distribution engineers need to learn, IEEE Trans. Power Systems, Vol. 19, pp. 17-23.

Venkatesh B., Rakesh Ranjan, and Gooi H.B., 2004. Optimal reconfiguration of radial distribution systems to maximize loadability, IEEE Trans. Power System, Vol. 19, No.1, pp. 260-266.

Zou K., Agalgaonkar A.P., Muttaqi K.M., and Perera S., 2009b. Voltage support by distributed generation units and shunt capacitors in distributed system, in IEEE Power \& Energy Society General Meeting. pp. 1-8.

Biographical notes

Ikbal Ali is Senior Assistant Professor in the Department of Electrical Engineering, Jamia Millia Islamia, New Delhi, India. He graduated from Zakir Hussain College of Engineering \& Technology, AMU, Aligarh. Received his M.Tech. degree from Indian Institute of Technology, Roorkee and he has been awarded the $\mathrm{Ph} . \mathrm{D}$. degree for his research work in the field of Substation Automation. His current research interests are in SCADA/EMS system, IEC 61850 based Substation Automation Systems, Substation Communication Networks Architecture, Power System Communication and Smart Grid. Dr. Ali is a senior member in IEEE and an expert lecturer on the topics related to Smart Grid Technologies, Substation Automation and Communication Networks for Substation Automation. 
Mini S. Thomas graduated from University of Kerala in 1984, completed her M.Tech from IIT Madras in1986 (both with gold medals) \& PhD from IIT Delhi in 1991, all in Electrical Engineering. Her employment experiences include Regional Engineering College, Calicut, Kerala, Delhi College of Engineering, New Delhi and presently as Professor In the Faculty of Engineering and Technology, Jamia Millia Islamia, New Delhi. Mini S. Thomas received the prestigious 'Career Award' for young teacher, instituted by AICTE, Govt. of India, for the year 1999. She has published over 70 papers in International/National Journals \& Conferences. Her current research interests are in SCADA/EMS System and Intelligent Protection of Power System. She is a senior member in IEEE.

Pawan Kumar is Assistant Professor in the Department of Electrical \& Electronics Engineering, Galgotias College of Engineering \& Technology, Greater Noida, U.P., India. He graduated from JMIT, Radaur, Kurukshetra University. Received his M.Tech. degree from Indian Institute of Technology, Delhi. He is the certified Energy Manager cum Auditor by BEE, Ministry of Power, Govt. of India. His main research interests are in the area of optimization techniques in Electrical Distribution System's Design, Operation and Control, and Energy Efficiency in Power Utilities, Distribution Automation and Smart Grid. He is a member in IEEE

Received December 2012

Accepted June 2012

Final acceptance in revised form June 2012 